\title{
The Relative Contribution of Patterns of Exposure to Community Violence in Predicting Aggressive Behaviours and Fear Among a Sample of Children in The Age (4-5 Years)
}

\author{
Mansour Mohammed Ali Bopaeda 8(D) \\ Lecturer, Department of Clinical psychology, Faculty of Arts \& Science Kufrah, Benghazi University, Libya \\ $\checkmark$ Corresponding Author: Mansour Mohammed Ali Bopaeda, E-mail: bopaedmansour@gmail.com
}

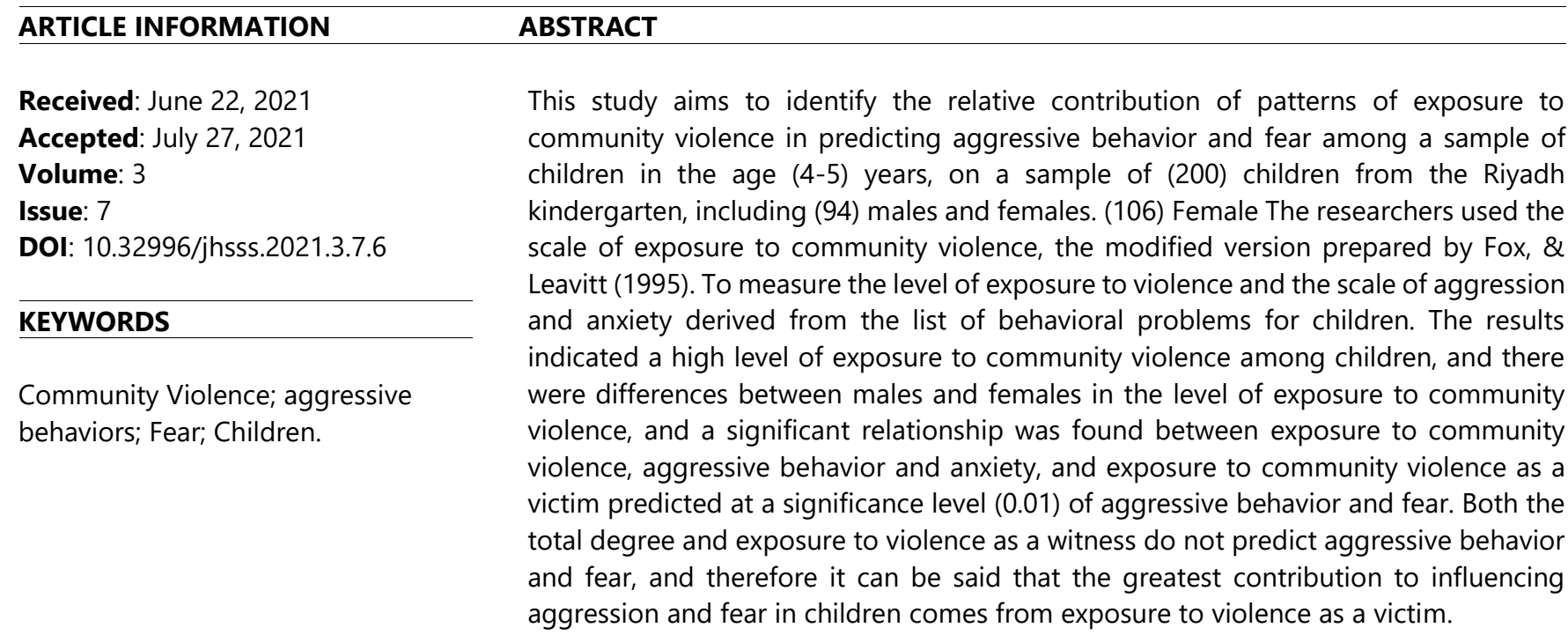

\section{Introduction}

While society is a source of protection and cohesion with children and adolescents, it can also be a source of threats and exposure to violence, including peer violence, violence related to guns and other weapons, gang violence, police violence, sexual violence, kidnapping, and trafficking, and violence may be associated with new media and ICTs. For some children and adolescents, the journey to and from school may be their first independent exposure to society, and it may be their first exposure to risk. Many children may also be exposed to societal violence while carrying out tasks at homes such as fetching water, fuel, or food.

Community violence is defined as: violence that occurs between people who are not related and may know each other or not, and generally occurs outside the home, and includes gang violence, random acts, sexual assault, rape, violence in schools and workplaces, carrying weapons, drugs, theft and other manifestations that may be exposed to it. The individual, whether a victim, witness, or hearer. (WHO, 2002, 2)

The continuous increase in children's exposure to societal violence has led to the interest of international organizations and bodies in this issue; Where statistics in the United States of America, for example, indicate that one out of every three children has been exposed as a victim to some form of violence throughout their lives, and nearly $90 \%$ of children have witnessed violent events (Richters and Martinez, 1993), as found by (Gorman-Smith et al. 2004), on a sample of (263) Americans of African and Latino descent, indicated that the rates of exposure to violence among children and youth are very high.

In light of these increasing rates, many researchers, in light of the increasing risk of violence and exposure to it, have been interested in conducting studies on the impact of exposure to violence on children, adolescents, and adults. For more reviews on these topics, refer to, for example, (Fostera \& Brooks-Gunnb, 2015; Wilson, Rosenthal, 2003; McDonald \& Richmond, 2008; van Rooij et al 2020). Studies indicate a negative impact of exposure to community violence on the mental and physical health of children and

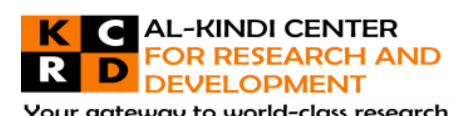

Your gateway to world-class research

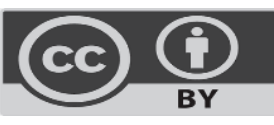

Published by Al-Kindi Center for Research and Development. Copyright (c) the author(s). This open access article is distributed under a Creative Commons Attribution (CC-BY) 4.0 license 
adolescents, and exposure to violence predicted statistically significant symptoms of post-traumatic stress disorder, depression, delinquency, and anxiety.

In addition to the negative effects of exposure to violence on the mental and physical health of adolescents, the direct and indirect economic costs of health care and legal costs are estimated at billions. In Latin America conducted by the Inter-American Development Bank, the cost of health care spending arising from exposure to violence was found to be $1.9 \%$ of GDP in Brazil, $5.0 \%$ in Colombia, $4.3 \%$ in El Salvador, $1.3 \%$ in Mexico, and 1.5\% in Peru and $0.3 \%$ in Venezuela. $($ WHO, 2002, 12)

In light of these results, whether related to the psychological and physical effects of exposure to violence on children and adolescents, or the high economic cost of health care in this field and the scarcity of studies in Libyan society in this field, researchers developed the necessity of conducting a study that sheds light on this subject, especially in light of the circumstances that Libyan society is going through. At the present time, due to the absence of the sovereign manifestations of the state and the proliferation of weapons, and therefore the problem of the current research was to study the relationship between exposure to societal violence, aggressive behavior, and fear among a sample of children in the age group of 4-6 years.

\subsection{Questions of the Study:}

The main questions of this study are as follows:

1. What are the rates of exposure to community violence among children age 4 to 5 years?

2. Are there differences between males and females in the rates of exposure to community violence?

3. What is the nature of the relationship among exposure to community violence, aggressive behavior, and fear among children in the current study?

4. What is the contribution of exposure to violence in predicting aggressive behavior and fear in this study?

\subsection{Objectives of the study}

The current study aims to try to identify the following:

- Identifying the rates of exposure to community violence among children in the current study.

- Identifying the differences between males and females in the rates of exposure to community violence.

- Identifying the relationship between exposure to societal violence, aggressive behaviors, and fear among children in the current study.

- $\quad$ Predicting aggressive behaviors and fear in light of the degree on the scale of exposure to community violence.

\subsection{The Importance of the Study:}

The importance of this study comes from the following points:

$>$ In light of what was previously presented about the prevalence rates of exposure to community violence and what the World Health Organization referred to as a global health problem, we can discern the importance of studying this issue in Libyan society and estimating its prevalence rates, especially in light of the political and economic conditions that Libya is going through at the present time.

$>$ The importance of the current study comes from the importance of the sample used in it, and they are children in the age group from 4 to 5 years; Since the exposure of children to forms of violence at this stage can have an impact on their personalities in the future, therefore, studying this topic helps us in making decisions related to children in order to avoid such problems.

$>$ The results of the current research can benefit in directing attention to this phenomenon, whether from those in charge of the educational process or from providers of mental health services, from the need to provide care and support to victims of exposure to community violence and to develop local and national policies to reduce the effects of this problem.

$>$ The current study opens the door to one of the topics that need further study and research on identifying risk factors and prevention factors associated with exposure to community violence.

\subsection{Limits of The Study:}

- Spatial limit: The current research was applied in the city of Kufra with four private kindergartens.

Time limit: The research was applied in the academic year 2020/2021.

- Human limit: the research was applied to a number of (200) children, including (94) males and (106) females.

\section{Literature Review}

2.1 Definition of community violence. 
Before presenting a definition of community violence, the concept of violence and its patterns must be defined in order to facilitate understanding the concept of community violence. The World Health Organization defined violence as: the deliberate use of physical force, whether by threat or real physical use against oneself, another person, a group of deprivation, or a community; There are many forms and classification patterns of violence, and perhaps the classification adopted by the World Health Organization in its report on violence and health in (2002) is one of the classifications that can be relied upon when studying the subject of Violence This classification categorizes violence into three main categories:

- Self-directed violence.

- Violence directed at persons.

- Collective violence.

Exposure to community violence falls in the classification under the second type (interpersonal violence) and is defined as: that manifestation of violence that occurs between individuals who are not related to them and may know some of them or not, and generally occurs outside the home and includes gang violence, random acts, sexual assault and violence in locations Institutions such as schools and workplaces.

\subsubsection{Theoretical framework explaining the relationship between exposure to community violence and mental health.}

There are many theoretical approaches explaining violence in light of the multiplicity and diversity of different theoretical orientations of the researchers. The researchers adopt the ecological model (environmental systems theory) as a framework for explaining the relationship between exposure to violence and the mental health of adolescents, according to Bronfenbrenner, 1979. The family, school, peers, neighbors, and society in general, in addition to the personal factors of adolescents themselves, and the impact of this multidimensional network varies according to its proximity or distance from the adolescent and includes four levels:

1- Individual level: It includes biological factors, personal history, educational and social background, childhood experiences, history of abuse and aggression, the nature and characteristics of parents, and in particular this level focuses on individual characteristics that increase the likelihood of a person becoming a victim or perpetrator of violence.

2- Relationships level: It reflects the environment most closely related to the child, including family, school, and friends' relationships, and this level explores how intimate social relationships - such as those of colleagues, closely related peers, and family members - can increase exposure to the risk of violent behaviors as a victim or as an offender. Studies have shown in the case of Interpersonal Violence Older children are more willing and likely to engage in negative activities if encouraged by their friends.

3- Societal level: It includes the societal systems in which social relations appear - schools, workplaces, and the nature of the neighborhood. Or high unemployment or characterized by problems such as drug trafficking and others.

4- Social level: This level investigates the larger social and cultural factors that affect the incidence of violence. It includes cultural norms that support violence as a method of conflict resolution, attitudes that refer to suicide as an issue of individual choice, criteria that support the use of excessive force by the police against civilians, and criteria that support suicide. political clashes.

According to this model, exposure to community violence is considered a factor in targeting risk through its direct impact on the development of the child, or through the indirect impact within the environment in which he lives, such as school, family, or with neighbors; For example, societal violence may cause disruption in the family system, such as: authoritarian parenting methods, changes in parent-child interactions, and an increase in family conflicts, which leads to children feeling unsupported, leading to more helplessness and depression behavioral problems.

Apparent behavioral patterns that reflect a violation of accepted social norms, directed by the individual towards others, or towards himself for the purpose of harm, which are behaviors that others can easily notice, and are characterized by repetition and severity, but do not reach the degree of severe disorder that requires therapeutic intervention, and these behaviors affect the individual's psychological efficiency and limit his interaction with others. (Kashif, 2004, 74)

\subsubsection{Aggressive behavior:}

Aggressive behavior is defined as: any behavior by an individual aimed at causing harm or harm to another individual or group of individuals trying to avoid this harm, whether it is physical or verbal, and whether it is done directly or indirectly, or expresses himself in the form of anger or hostility directed at The victim. (Abdullah, B.T., 169)

\subsubsection{The Fear:}


Fear is defined as "an emotional state accompanied by psychological and physical agitation, which afflicts the child when an external influence causes him to feel danger, and this influence may emanate from within the child. And life also belongs to other creatures (Sulaiman, 2005. 21)

\subsection{Previous Studies:}

Several studies have been conducted that dealt with societal violence, especially in light of the growing phenomenon of exposure to violence, in order to identify the effects of exposure to this type of violence on the physical and mental health of individuals. current. Conducted by Melanie, et al, 2000). A study aimed at identifying the impact of exposure to community violence as a victim and as a witness on trauma reactions and behavioral problems among a sample of 181 African-American children living in lowincome areas. The results of the regression analysis indicated that exposure to violence as a victim significantly predicted behavioral problems. Also, the societal chaos largely predicted the traumatic reactions of children.

In an attempt to link exposure to community violence and anti-social behaviors, Amelia \& Andrew (2000) conducted a study to identify the relationship between exposure to community violence, anti-social behaviors, and social behaviors, on a sample of 78 seventh-grade children with an average age of 12.8 years in South The results of the study indicated that there is a medium relationship between direct exposure to violence and levels of aggression and difficulties in self-regulation, and gender more significantly predicted aggressive behaviors than direct exposure to violence.

In a review of the research heritage that dealt with the impact of exposure to community violence on children and adolescents, Tener (2001) concluded that exposure to community violence is significantly associated with post-traumatic stress and depression in children and adolescents. Nancy, Huesmann, Anja, 2003 also conducted a study aimed at identifying the relationship between exposure to community violence, social knowledge, and aggression in a sample of 4458 children from urban areas in the age group from 5 to 12 years, and the results of the study indicated that That social knowledge mediates the relationship between exposure to community violence and aggressive behaviors, and this result indicates that witnessing community violence affects aggressive behaviors through both the imitation of violent behaviors and the development of social perceptions associated with it as children age.

In an attempt to determine the reasons behind some of the unexplained physical complaints in children, some research has linked these complaints to exposure to community violence, and these studies include the study of Bailey, Dillense, Henginen, Wager, Robert, and Covington (Bailey, et al, 2005). Which aimed to identify the nature of the relationship between physical complaints and exposure to community violence, on a sample of 268 African-American children in the age group from 6 to 7 years, and the results of the study indicated that there is a relationship between witnessing community violence and stress symptoms. Psychological difficulties sleep difficulties, stomach complaints, and headaches. Exposure to community violence also accounted for $10 \%$ of the variation in symptoms of stress among children, and exposure to community violence as a victim increased by $28 \%$. Appetite problems in children increased by $94 \%$ of sleep problems and by $57 \%$ of headaches, and these indicate The results indicate the need to take this dimension into account when treating these cases

Linda and others (Linda, et al, 2008) also conducted a study to identify the effect of exposure to community violence, the conflict between parents, parental positivity, and informal social support in predicting social skills and behavioral problems in a sample of 184 children. Societal violence significantly predicts behavioral problems in children and low levels of self-control and cooperation, and conflicts between spouses significantly predict internal problems in children.

In South Africa, Shields and others (Shields et al, 2008) conducted a study to identify the impact of community violence on children in Cape Town, South Africa, and also aimed to identify the relationship between exposure to community violence and psychological distress among a sample of children in the age group. From 8 to 13 years, the study sample consisted of 185 children who were randomly selected from schools from this city. The results indicated that exposure to all forms of violence was statistically significant, and older children were exposed to greater manifestations of violence compared to younger children. The results also indicated that social support, family planning, and family monitoring of children are considered preventive variables from exposure to community violence, and the relationship between exposure to murder and psychological distress was not statistically significant.

Patrck and others (Patrck, et al, 2009) conducted a study aimed at identifying the impact of exposure to community violence on mental health, in a post-analysis of 114 studies that dealt with the relationship between exposure to community violence and some different psychological variables, and the results indicated that there is a strong influence Societal violence in post-traumatic stress disorder and external problems, and exposure to violence as a victim significantly predicted symptoms of trauma compared to exposure to violence as a witness or as a listener, and witnessing violence had a significant impact compared to hearing violence on external problems, but both types of violence had an equal effect In internal problems, a strong relationship was found between external behavior and exposure to violence, and this relationship was very strong among children in internal problems. 
In an attempt to identify the relationship between exposure to community violence and internal and external problems among children in the age group from 8 to 16 years, Corgolin Franklin (Corigliano, \& Frank 2011) conducted a study on a sample of 43 children, and the results indicated that $93 \%$ of the sample members They were subjected to witnessing societal violence (rape, shooting, assault), and $55.8 \%$ of them were directly exposed to community violence at least once, and a direct and statistically significant relationship was found between exposure to community violence and emotional and behavioral functions, and exposure to violence as a victim was significantly related. External symptoms and exposure to violence as a viewer were associated with internal symptoms.

Fleckman et al (2016) studied the relationship between external behaviors and indirect exposure to violence, and its evaluation within the family and at the community level, as well as the interactive effect of indirect and direct exposure to violence on a sample of (82) children aged 4- 15 years and external behavior was assessed through the Child Behavior Checklist (CBCL) and the results indicated that exposure to indirect, direct and cross-contextual violence affects children's external behaviors. In addition, the findings suggest that societal and family social environments are both important targets for interventions designed to reduce extrinsic behaviors and improve long-term outcomes for youth at risk of experiencing violence.

In view of the role that exposure to community violence plays in influencing the behavior of children and adolescents, van Rooij et al (2020) was interested in identifying the impact of exposure to trauma, such as growing up in a violent neighborhood, as well as the stage of development, on the structure and function of the brain on a sample of (69) The variables were evaluated using magnetic resonance imaging (MRI) and the results indicated the impact of exposure to trauma broadly and exposure to violence more specifically, as well as the developmental stage on the neural circuits of fear in children and adolescents aged 8 to 14 years. Decreased hippocampal volume and increased amygdala volume were observed with increased levels of exposure to trauma, and higher levels of exposure to violence were associated with increased activation in the amygdala, hippocampus, and ventromedial prefrontal cortex during emotional response inhibition. This association was specifically observed in children younger than 10 years old. Finally, increased functional connectivity between the amygdala and brainstem was associated with higher levels of exposure to violence. Based on these findings, it can be hypothesized that exposure to trauma during childhood leads to structural changes associated with later risk for mental disorders. The brain has to adapt functionally to this situation in a way that promotes survival, in which the long-term costs or consequences of these adaptations are largely unknown and the scope for adaptation is largely unknown. future investigations.

Sehgal, \& Nayak, (2021). A study aimed at identifying some factors associated with aggressive behavior in children on a sample of (102) children in the age group from 10 to 12 years. The Children's Aggression Scale - Teacher Edition (CAS-T) was used. At this stage, children who were subjected to physical abuse and violence on television showed higher levels of violence compared to other children.

Through the previous presentation of some of the previous studies, it can be said that there is strong empirical support for the relationship between community violence and each of the internal and external problems in children, and among most of these problems, which were proven by the results of post-analysis and other studies, is their relationship to exposure to community violence, delinquency, aggressive behavior, anxiety, fear and the following stress disorder For shock, anxiety, and depression.

\section{Methodology}

\subsection{Method of the Study}

The author used the descriptive, correlative, comparative approach, due to its suitability to the nature and objectives of the current study. Where some descriptive studies try not to be limited to revealing the nature of the phenomenon and the relationship between the variables included in it, but rather to compare the similarities and differences between the phenomena (Van Dalen, 2010).

\subsection{Research design}

The author used a cross-sectional correlational research design, and this design falls under the non-experimental research designs. Where the author makes the measurements without changing the phenomenon or the situation that is subject to the measurement.

\subsection{Population and Sample of the Study}

The population consists of (600) children distributed over (10) kindergartens representing all the private kindergartens in Kufra city. The study sample was drawn from (200) children distributed over (5) kindergartens who are enrolled in the private kindergartens in Kufra. It is shown in the following table:

Table (1) Distribution of the study sample by kindergarten

\begin{tabular}{|l|l|l|l|}
\hline Kindergarten Name & Male & Female & Total \\
\hline
\end{tabular}




\begin{tabular}{|l|l|l|l|}
\hline & & & \\
\hline Kindergarten Ahbab Rahman & 30 & 20 & 50 \\
\hline Al Manahil Kindergarten & 21 & 23 & 44 \\
\hline Libyan Creativity Kindergarten & 15 & 30 & 45 \\
\hline Al Basateen Kindergarten & 11 & 15 & 26 \\
\hline Al Amal Kindergarten & 17 & 18 & 35 \\
\hline Total & $\mathbf{9 4}$ & $\mathbf{1 0 6}$ & $\mathbf{2 0 0}$ \\
\hline
\end{tabular}

\subsection{Tools of Data Collect}

The author used the following tools to measure the research variables:

violence exposure scale for children -revised to measure exposure to community violence in children in the study, the researchers used the scale of exposure to community violence, the modified form prepared by Fox and Leavitt (FOX, N \& Leavitt, l.a, 1995); Where they emailed him and obtained the original copy and agreed with it. A scale is a self-assessment tool suitable for ages from 4 to 10 years. It consists of 22 items dealing with forms of violence that children are exposed to or witnessing in their lives, and these items are displayed In the form of a story that the interviewer reads to the child, as it seems more understandable and appropriate for the child's age; Each paragraph of the scale is presented in the form of a cartoon depicting the meaning of the paragraph, and below the drawing, there is an estimated scale in the form of a thermometer that shows the amount of exposure to the situation, whether as a witness or as a victim; Where the grade is graded according to four estimates from (never) and gives the degree zero, and (once) and gives the degree one, and (many times) and gives the degree two, and (many times) and gives the degree three. The scale has good psychometric properties in its foreign form.

\subsection{Validity and reliability of the scale in the current study}

\section{- The veracity of the scale}

To verify the validity of the scale in the current study, the author applied it to a sample of (200) kindergarten children and used the method of internal consistency by calculating the correlation coefficients between the items' scores and the total score for each of the dimensions under which these items fall. The following table shows the values of the correlation coefficients and their statistical significance.

Table (2) the internal consistency coefficients for the scale of exposure to community violence

\begin{tabular}{|c|c|c|c|}
\hline \multicolumn{2}{|c|}{ Exposure to community violence as a witness } & \multicolumn{2}{|c|}{ Exposure to community violence as a victim } \\
\hline Item No & correlation coefficient & Item No & correlation coefficient \\
\hline A. 1 & $0.47^{* *}$ & 2 & 0.62 ** \\
\hline 3 & $0.41^{\star *}$ & 1) 4 & $0.59^{* *}$ \\
\hline 5 & $0.61^{* *}$ & 6 & $0.51^{\text {** }}$ \\
\hline 2) 7 & $0.62^{\star *}$ & 8 & $0.59^{\star *}$ \\
\hline 9 & $0.38^{\star \star}$ & 10 & $0.50^{\star \star}$ \\
\hline 11 & $0.57^{* \star}$ & 12 & $0.41^{* \star}$ \\
\hline 13 & $0.58^{\star \star}$ & 14 & $0.69 * \star$ \\
\hline 15 & $0.60^{\star \star}$ & 16 & $0.36^{\star \star}$ \\
\hline 17 & $0.63^{* *}$ & 22 & $0.48^{\star \star}$ \\
\hline 18 & $0.44^{\star *}$ & & \\
\hline 19 & $0.60^{\star *}$ & & \\
\hline 20 & $0.55^{\star \star}$ & & \\
\hline 21 & $0.39^{\star *}$ & & \\
\hline
\end{tabular}


It is clear from the previous table that there is a positive and significant correlation at the level of significance (0.01) for all items related to the dimension of exposure to violence as a witness and exposure to violence as a victim and the overall score for each of them, which indicates good validity coefficients of the scale.

As for the reliability, it was estimated on the same sample of honesty using the method of internal consistency by calculating the equation of one thousand Cronbach, and the value of one for the dimension of exposure to violence as a witness was 0.89 and for the dimension of exposure to violence as a victim was 0.85 and for the scale as a whole 0.91 and all of them indicate good reliability coefficients for the scale.

\subsection{Behavioral problems scale.}

To measure aggression and fear in the current study, two sub-scales were relied on from the list of behavioral problems prepared by (Omar, 2002), which are the scale of aggression and fear.38 items to measure fear, and the list has good psychometric properties; The results of the factor analysis indicated the saturation of the paragraphs on the different dimensions, with statistically significant percentages. As for the scale of aggression and fear used in the current study, the results indicated that the aggressive factor contributed 15.57 percent of the total variance of the scale, and the fear factor contributed 17.16 percent of the total variance of the scale.

With regard to stability, the results of the stability analysis using the re-test method indicated that there is a relationship between the first and second applications with correlation coefficients that ranged between (0.90 to 0.95$)$, which are significant values and indicate satisfactory stability coefficients for the list.

\subsection{The validity and reliability of the scale of aggression and fear in the study:}

To verify the stability of the two scales in the current study, the researcher applied them to a sample of 100 children from Riyadh kindergarten in the city of KUfra. The validity was estimated by internal consistency by calculating the correlation coefficients between the degree on each item and the total score of the scale, whether for lying or aggression. The following table shows the values of Correlation coefficients and their statistical significance.

Table (3) Internal consistency coefficients for the scale of aggression and fear

\begin{tabular}{|c|c|c|c|c|c|}
\hline \multicolumn{4}{|c|}{ Aggression } & \multicolumn{2}{|l|}{ Fear } \\
\hline Item & correlation & Item & correlation & Item & correlation \\
\hline 1 & $.45^{\star *}$ & 21 & $.69 * \star$ & 1 & $.61^{* *}$ \\
\hline 2 & $.62^{* *}$ & 22 & $.75^{\star \star}$ & 2 & $.47^{\star *}$ \\
\hline 3 & $.53^{* \star}$ & 23 & $.47^{* *}$ & 3 & $.60 * *$ \\
\hline 4 & $.492^{* \star}$ & 24 & $.47^{* \star}$ & 4 & $.74^{* *}$ \\
\hline 5 & $.485^{\star *}$ & 25 & $.50 * *$ & 5 & $.64^{* *}$ \\
\hline 6 & $.63^{* *}$ & 26 & $.61^{* *}$ & 6 & $.62^{* *}$ \\
\hline 7 & $.458^{\star *}$ & 27 & $.42^{*}$ & 7 & $.45^{* *}$ \\
\hline 8 & $.32^{* *}$ & 28 & $.77^{\star \star}$ & 8 & .50 ** \\
\hline 9 & $.58^{\star \star}$ & 29 & $.71^{* *}$ & 9 & $.72^{\star \star}$ \\
\hline 10 & .59 ** & 30 & $.67^{\star \star}$ & 10 & $.63^{* *}$ \\
\hline 11 & $.46^{\star \star}$ & 31 & $.53^{\star \star}$ & 11 & $.49^{* *}$ \\
\hline 12 & $.47^{\star \star}$ & 32 & $.66^{\star *}$ & 12 & $.67^{\star *}$ \\
\hline 13 & $.65^{* *}$ & 33 & $.53^{* *}$ & 13 & $.84^{* *}$ \\
\hline 14 & $.72^{\star *}$ & 34 & $.40^{*}$ & 14 & $.52^{*}$ \\
\hline 15 & $.63^{* *}$ & 35 & $.70^{\star *}$ & 15 & $.73^{\star *}$ \\
\hline 16 & $.48^{* *}$ & 36 & $.65^{\star *}$ & 16 & $.62^{*}$ \\
\hline 17 & $.66^{\star *}$ & 37 & $.55^{\star \star}$ & 17 & $.61^{* *}$ \\
\hline 18 & $.38^{*}$ & 38 & $.43^{* *}$ & 18 & $.66^{* *}$ \\
\hline 19 & $.44^{\star *}$ & 39 & $.67^{\star \star}$ & 19 & $.55^{\star *}$ \\
\hline 20 & $.75^{\star \star}$ & & & & \\
\hline
\end{tabular}

By reviewing the data contained in Table No. (3), it can be said that all the items' correlation coefficients with the total degree of the dimension came at a significance level of (0.01), which indicates good validity coefficients for the two scales. 
With regard to stability, it was estimated on the same sample of honesty using the Alf Cronbach equation, and the value of the Ale coefficient for the aggressive dimension (0.88) and the fear dimension (0.90), which are significant and satisfactory values, which indicates good stability coefficients for the two dimensions.

\subsection{Research Procedures and Ethics:}

The tools of the current study were applied in the academic year (2020-2021). The application was carried out individually with the participation of female teachers with regard to the scale of exposure to community violence, and the scale of behavioral problems was the assessment by the teacher.

\subsection{Statistical methods used:}

The Statistical Package for the Humanities (SPSS) program was used to analyze the data for the study, and the following statistical methods were used:

1- Means and standard deviations.

2 - T-test for the significance of the differences between the averages.

3 Regression analysis.

4 Frequencies and percentages.

\section{The Results and Their Discussion:}

\subsection{The Result of the First Question:}

This question states: What are the rates of exposure to community violence among children in the current study?

To answer this question, the frequencies and percentages of students' grades equal to or greater than their grades in the higher spring were calculated. The following table shows the result of this procedure.

Table (4) Frequencies and percentages of students' scores that are equal to or greater than their scores in the higher spring

\begin{tabular}{|c|c|c|c|c|c|c|c|c|}
\hline \multirow[t]{2}{*}{ Variables } & \multicolumn{3}{|l|}{ Male } & \multicolumn{3}{|c|}{ Female } & \multicolumn{2}{|c|}{ Total Sample } \\
\hline & $\begin{array}{l}\text { Cut } \\
\text { Score }\end{array}$ & Frequency & percentage & $\begin{array}{l}\text { Cut } \\
\text { Score }\end{array}$ & Frequency & percentage & Frequency & percentage \\
\hline $\begin{array}{l}\text { Exposure } \\
\text { as a } \\
\text { witness }\end{array}$ & 15 & 27 & $28.27 \%$ & 13 & 23 & $23.58 \%$ & 50 & $25 \%$ \\
\hline $\begin{array}{l}\text { Exposure } \\
\text { as a } \\
\text { victim }\end{array}$ & 7 & 22 & $23.40 \%$ & 5 & 20 & $18.86 \%$ & 42 & $21 \%$ \\
\hline $\begin{array}{l}\text { Total } \\
\text { marks }\end{array}$ & 17 & 25 & $26.59 \%$ & 14 & 21 & $19.81 \%$ & 45 & $22.5 \%$ \\
\hline
\end{tabular}

Through the previous table, it can be said: The rates of exposure to violence among the sample members, according to the highest spring degrees, ranged from (18.86 to $28.27 \%$ ). It can be said that these rates are considered high, which indicates the existence of manifestations of children's exposure to violence. These manifestations include beating, kicking, death threats, and theft with respect to the aspects measured by the scale. These results agree with the findings of (Dawes et al., 2006) and (Shields. $n$, Nadasen. $k$, Pierce, 2008) study on the high rates of exposure to societal violence, and this result seems logical given the political instability that Libya is going through in at the present time, the spread of weapons and the absence of many institutions that were working in maintaining local peace and security.

\subsection{The Result of the Second Question:}

This question states: Are there differences in exposure to societal violence between males and females?

To answer this question, the $t$ value of the differences between the averages was calculated, and the following table shows this procedure.

Table (5) "T" value of the differences between males and females in exposure to community violence

\begin{tabular}{|l|l|l|l|l|}
\hline Variables & Males (96) & Females (104) & T value & sig \\
\hline
\end{tabular}




\begin{tabular}{|l|l|l|l|l|l|l|}
\hline & mean & $\begin{array}{l}\text { standard } \\
\text { deviation }\end{array}$ & mean & $\begin{array}{l}\text { standard } \\
\text { deviation }\end{array}$ & & \\
\hline $\begin{array}{l}\text { Exposure to } \\
\text { community } \\
\text { violence as a } \\
\text { witness }\end{array}$ & $\mathbf{8 . 5 5}$ & $\mathbf{5 . 0 5}$ & $\mathbf{7 . 3 0}$ & $\mathbf{4 . 8 9}$ & $\mathbf{1 . 6 6}$ & $\mathbf{0 . 0 9}$ \\
\hline $\begin{array}{l}\text { Exposure to } \\
\text { community } \\
\text { violence as a } \\
\text { victim }\end{array}$ & $\mathbf{3 . 6 8}$ & $\mathbf{3 . 0 5}$ & $\mathbf{2 . 2 0}$ & $\mathbf{2 . 6 0}$ & $\mathbf{3 . 4 6}$ & $\mathbf{0 . 0 0 1}$ \\
\hline $\begin{array}{l}\text { Total degree } \\
\text { of exposure } \\
\text { to community } \\
\text { violence }\end{array}$ & $\mathbf{1 2 . 2 3}$ & $\mathbf{6 . 7 4}$ & $\mathbf{9 . 5 0}$ & $\mathbf{5 . 9 9}$ & $\mathbf{2 . 8 4}$ & $\mathbf{0 . 0 1}$ \\
\hline
\end{tabular}

From the previous table, it is clear that there are statistically significant differences between males and females in exposure to community violence as a victim and the total degree of exposure, while there were no differences in exposure to community violence as a witness. This result is partially consistent with the results of psychological heritage in this field; Where many studies indicated that there are sexual differences between males and females in exposure to societal violence and its consequences, and these studies study each of (Breslau \& Anthony, 2007; Breslau, et al, 2004). This result can be explained that male children in society have greater freedom of movement and interaction than females, and therefore are exposed to situations that may represent a threat to them, and this was confirmed that the differences were not significant in exposure to violence as a witness while it was significant in exposure to violence as a victim.

\subsection{The Result of the Third Question}

This question states: What is the nature of the relationship between exposure to community violence, aggressive behaviors, and fear among children in the current study?

To answer this question, the Pearson correlation coefficient was calculated between the responses of the sample members on the scale of exposure to community violence and the parameter estimates of aggressive behaviors and fear. The following table shows the result of this procedure.

Table (6) Correlation coefficients between the variables of exposure to community violence, aggressive behaviors, and fear

\begin{tabular}{|l|l|l||}
\hline Variables & Aggressive Behaviours & Fear \\
\hline $\begin{array}{l}\text { Exposure to community violence as } \\
\text { a witness }\end{array}$ & $* * \mathbf{0 . 2 0}$ & ${ }^{* \mathbf{0 . 1 6}}$ \\
\hline $\begin{array}{l}\text { Exposure to community violence as } \\
\text { a victim }\end{array}$ & $* * \mathbf{0 . 3 2}$ & $* * \mathbf{0 . 3 2}$ \\
\hline Total exposure to violence & $* * \mathbf{0 . 2 9}$ & $\mathbf{w}^{* \mathbf{0 . 2 6}}$ \\
\hline
\end{tabular}

(** Significant at 0.01 level * Significant at 0.05)

Through the previous table, it is clear that there is a positive and statistically significant relationship at a significance level less than $(0.01)$ and (0.05) between exposure to community violence as a witness and as a victim and the total degree of exposure to violence and aggressive behaviors and fear, and this result is consistent with the studies of (Bolland, et al, 2011; Brady, et al 2008; Lambert, Boyd, Cammack, \& lalongo, 2012). ; Where the results of these studies indicated that there is a positive and significant relationship between exposure to community violence and aggressive behavior, while it differs, and this result can be explained in the light of Bandura's social learning theory, A. 1986). This indicated that aggressive behaviors are learned by the child by observing the patterns in the child's surroundings, and thus children practice aggressive behaviors in response to what they are exposed to and they notice from patterns of exposure to violence in the school, the street, and the area in which they live. 


\subsection{The Result of the Fourth Question}

This question states: What is the contribution of exposure to violence in predicting aggressive behaviors and fear in the eyes of the study?

To answer this question, a simple regression analysis of aggression and fear was used as dependent variables and exposure to community violence as an independent variable. The following table shows the regression value and its significance.

Table (7) Regression analysis to predict aggressive behaviors in the light of children's scores on the scale of exposure to community violence

\begin{tabular}{|c|c|c|c|c|c|c|c|c|}
\hline \multirow{2}{*}{\multicolumn{2}{|c|}{ Model }} & \multicolumn{2}{|c|}{$\begin{array}{l}\begin{array}{l}\text { Unstandardized } \\
\text { Coefficient } \\
\text { s }\end{array} \\
\end{array}$} & \multirow{2}{*}{$\begin{array}{l}\text { Standardize } \\
\text { d } \\
\text { Coefficients } \\
\text { Beta }\end{array}$} & \multirow[t]{2}{*}{$\begin{array}{l}\text { Value } \\
\text { (T) }\end{array}$} & \multirow[t]{2}{*}{$\begin{array}{l}\text { Indicatio } \\
\text { n Level }\end{array}$} & \multicolumn{2}{|c|}{ Form Validity } \\
\hline & & B & $\begin{array}{l}\text { Std } \\
\text { Error }\end{array}$ & & & & Value (F) & $\begin{array}{l}\text { Indication } \\
\text { Level }\end{array}$ \\
\hline \multirow[t]{3}{*}{$\begin{array}{l}\text { Aggressio } \\
\mathrm{n}\end{array}$} & $\begin{array}{l}\text { Constant } \\
\text { Gradient }\end{array}$ & 8.739 & 0.585 & & $\begin{array}{l}14.92 \\
7 \\
\end{array}$ & 0.000 & 11.651 & $.000 \mathrm{~b}$ \\
\hline & $\begin{array}{l}\text { Being } \\
\text { subjecte } \\
d \text { to } \\
\text { violence } \\
\text { as a } \\
\text { victim }\end{array}$ & 0.037 & 0.017 & 0.318 & 2.177 & 0.031 & $\begin{array}{l}\text { Correlatio } \\
\mathrm{n} \\
\text { Coefficient }\end{array}$ & $\begin{array}{l}\text { Coefficient Of } \\
\text { Determinatio } \\
\mathrm{n}\end{array}$ \\
\hline & $\begin{array}{l}\text { Total } \\
\text { degree } \\
\text { of } \\
\text { violence }\end{array}$ & 0.001 & 0.009 & 0.009 & 0.059 & 0.953 & .325 & 0.106 \\
\hline \multirow[t]{4}{*}{ Fear } & $\begin{array}{l}\text { Constant } \\
\text { Gradient }\end{array}$ & 12.725 & 0.960 & & $\begin{array}{l}13.25 \\
3 \\
\end{array}$ & 0.000 & Value (F) & $\begin{array}{l}\text { Indication } \\
\text { Level }\end{array}$ \\
\hline & $\begin{array}{l}\text { Being } \\
\text { subjecte } \\
d \text { to } \\
\text { violence } \\
\text { as a } \\
\text { victim }\end{array}$ & 0.073 & 0.028 & 0.388 & 2.657 & 0.009 & 11.473889 & .000 \\
\hline & $\begin{array}{l}\text { Total } \\
\text { degree } \\
\text { of } \\
\text { violence }\end{array}$ & -0.008 & 0.015 & -0.075 & -0.516 & 0.606 & $\begin{array}{l}\text { correlation } \\
\text { coefficient }\end{array}$ & $\begin{array}{l}\text { coefficient of } \\
\text { determination }\end{array}$ \\
\hline & \multicolumn{6}{|c|}{ Exposure to violence as a witness was excluded from the regression model } & .323 & 0.104 \\
\hline
\end{tabular}

From the previous table, it can be said that the total degree of exposure to community violence and exposure to violence as a victim predicted, in a statistically significant way, at a significance level (0.01) of aggressive behaviors and fear. For fear, the greatest effect of exposure to violence was as a victim, where the beta value for aggression was (0.31) and for fear (0.38). This result is consistent with the results of the studies of (Bolland, et al, 2011; Brady, et al 2008; Lambert, Boyd, Cammack, \& lalongo). This result can be explained in light of the severe impact of being a victim of violence, which is a manifestation of the threat to physical integrity, which in turn generates negative reactions that affect the mental and psychological health of the victims of this violence.

\section{Recommendations and Suggested of the Study}

In light of the results obtained in the current study, the author recommends the following:

$>$ In light of what the results of the current study and many previous studies indicated to the existence of a relationship between exposure to community violence and the mental health of children, the author recommends the need to prepare early intervention programs targeting children most exposed to manifestations of community violence and to establish an action plan to prevent violence and implement it within schools and kindergartens.

$>$ The necessity of educating parents and teachers about the dangers of exposure to societal violence on children, especially in giving them manifestations of aggressive behaviors. 
Providing social support, prevention programs, and other services to protect families at risk of being exposed to community violence.

$>$ Spreading the collective awareness of this issue through the audio, visual, and written media.

$>$ The necessity of providing mental health services to children exposed to community violence so that the future effects of this violence on them and on society, in general, can be avoided.

$>$ Conducting more studies on the effects of exposure to community violence on the mental and physical health of children, adolescents, and adults in different regions and locations.

\section{References}

[1] Amelia V. der M. \& Andrew D. (2010). Prosocial and antisocial tendencies in children exposed to community violence. Southern African Journal of Child and Adolescent Mental Health. 12(1), 19-37.

[2] Bailey, B. N., Delaney-Black, V., Hannigan, J. H., Ager, J., Sokol, Robert., Covington, CY. (2005). Somatic complaints in children and community violence exposure. Journal of Development \& Behavioral Pediatrics: 26(5), 341-348.

[3] Bandura, A. (1986). Social foundations of thought and action: A social cognitive theory.Englewood Cliffs, NJ: Prentice Hall.

[4] Bell C and Jenkins E (1991) Traumatic stress and children. Journal of Health Care for the Poor and Undeserved 2: 175-185.

[5] Bolland, J., Henly, S., Sieving, R., \& Stoddard, S. (2011). Social connection, trajectories of hopelessness, and serious violence in impoverished urban youth. Journal of Youth and Adolescence, 40, 278-295. doi:10.1007/s10964-010-9580-x

[6] Brady, S., Gorman-Smith, D., Henry, D., \& Tolan, P. (2008). Adaptive coping reduces the impact of community violence exposure on violent behavior among African American and Latino male adolescents. Journal of Abnormal Child Psychology, 36, 105-115 doi:10.1007/s10802007-9164-x

[7] Breslau N, Anthony J. C. (2007) Gender differences in the sensitivity to posttraumatic stress disorder: An epidemiological study of urban young adults. Journal of Abnormal Psychology; 116:607-611

[8] Breslau N., Chilcoat H. D., Kessler RC., Davis GC. (1999) Previous exposure to trauma and PTSD effects of subsequent trauma: Results from the Detroit Area Survey of Trauma. American Journal of Psychiatry; 156:902-907.

[9] Breslau N, Kessler R. C, Chilcoat H, Schultz L. R, Davis G. C, Andreski P. (1998) Trauma and posttraumatic stress disorder in the community: The 1996 Detroit Area Survey of Trauma. Archives of General Psychiatry; 55:626-632.

[10] Breslau N, Peterson E. L, Poisson L. M, Schultz L. R, Lucia V. C. (2004) Estimating post-traumatic stress disorder in the community: Lifetime perspective and the impact of typical traumatic events. Psychological Medicine; 34:889-898.

[11] Bronfenbrenner, U. (1979). The ecology of human development: Experiments by nature and design. Cambridge, MA: Harvard University Press.

[12] Chen, P., Voisin, D. R., \& Jacobson, K. C. (2013). Community violence exposure and adolescent delinquency: Examining a spectrum of promotive factors. Youth \& Society.doi:10.1177/0044118X13475827

[13] Cooley-Quille, M., Boyd, R. C., Frantz, E., \& Walsh, J. (2001). Emotional and behavioral impact of exposure to community violence in innercity adolescents. Journal of Clinical Child Psychology, 30(2), 199-206.

[14] Corigliano, M., Frank J. (2001). Community violence exposure and behavioral and emotional functioning among African American and lation children and adolescents in a nonpsychiatric inpatient sample. Unpublished doctoral. John's University (New York), ProQuest Dissertations Publishing, 3483406

[15] Dawes, A., Long, W., Alexander, L. \& Ward, C. L. (2006). A situation analysis of children affected by maltreatment and violence in the Western Cape. A Report for the Research Directorate, Department of Social Services \& Poverty Alleviation: Provincial Government of the Western Cape. Cape Town: Human Sciences Research Council

[16] Duckworth-Melanie P., Danielle H, \& Scott D. (2000). Influence of interpersonal violence and community chaos on stress reactions in children, Journal of Interpersonal Violince.15(8):806-26

[17] Fleckman, J. M., Drury, S. S., Taylor, C. A., \& Theall, K. P. (2016). Role of direct and indirect violence exposure on externalizing behavior in children. Journal of urban health, 93(3), 479-492.

[18] Fostera, H \& Brooks-Gunnb, J. (2015). Children's Exposure to Community and War Violence and Mental Health in Four African Countries: A Stress Process Model Social Science Medicine, 146, 292-299. doi: 10.1016/j.socscimed.2015.10.020. Epub 2015 Oct 20.

[19] Fox, N. A., \& Leavitt, L. A. (1995). Violence Exposure Scale-Revised (VEX-R).

[20] Gorman-Smith, D., Henry, D. B., \& Tolan, P. (2004). The role of exposure to community violence and violence perpetration: The protective effects of family functioning. Journal of Clinical Child and Adolescent Psychology, 33, 439-449

[21] Gorman-Smith D, Henry D and Tolan P (2004) Exposure to community violence perpetration: The protective effects of family functioning. Journal of Clinical Child and Adolescent Psychology 33: 439-449.

[22] Kessler R. C, Sonnega A, Bromet E, Hughes M. (1995) Posttraumatic stress disorder in the National Comorbidity Survey. Archives of General Psychiatry;52(12):1048-1060.

[23] Kessler R.C. (1995) The national comorbidity survey: Preliminary results and future directions. International Journal of Methods in Psychiatric Research;5(2):139-151.

[24] Lambert, S. F., Boyd, R. C. Cammack, N. L., \& lalongo, N. S. (2012). Relationship proximity to victims of witnessed community violence: Associations with adolescent internalizing and externalizing behaviors. American Journal of Orthopsychiatry,82, 1-9.doi:10.1111/j.19390025.2011. 01135.x

[25] Linda M., Sally A., Koblinsky, S. M. (2008). Community violence, interpartner conflict, parenting, and social support as predictors of the social competence of African American preschool children. Journal of Black Psychology. v34 n2 p192-216 
[26] Mcdonald, C. C. \& Richmond, T. R. (2008). The relationship between community violence exposure and mental health symptoms in urban adolescents. Journal of Psychiatric and Mental Health Nursing 15, 833-849.

[27] Nancy G. G., Rowell H., and Anja S. (2003). Community violence exposure, social cognition, and aggression among urban elementary school children. Child Development, 74(5), 1561-1576.

[28] Nancy S., Kathy N., Lois P. (2008). The effects of community violence on children in cape town, South Africa. Child Abuse \& Neglect 32589601.

[29] Patrck J. F., Carolyn J. T., Jordan M. B. (2009). Community Violence: A meta-analysis on the effect of exposure and mental health outcomes of children and adolescents. Development and Psychopathology, 21, 227-259.

[30] Richters, J. E., and Martinez, P. E. (1993). The NIMH community violence project: I. Children as victims of and witnesses to violence. Psychiatry, 56, 7-21

[31] Richters, J.E., \&Martinez, P. (1993). The NIMH Community Violence Project: I. Children as victims of and witnesses to violence. Psychiatry, 56, 7-21.

[32] Stein J, Gelberg L. (1997) Comparability and representativeness of clinical homeless, community homeless, and domiciled clinic samples: Physical and mental health, substance use, and health services utilization. Health Psychology; 16:155-162.

[33] Sehgal, M., \& Nayak, A. S. (2021). Aggresssion in School Children: Role of Gender, Family Factors, and Exposure to Violence. medRxiv

[34] Tener G. V. (2001). Children's Exposure to Community Violence. Journal of Nursing Scholarship,33:2, 167-173.

[35] Van-Rooij, S. J., Smith, R. D., Stenson, A. F., Ely, T. D., Yang, X., Tottenham, N., ... \& Jovanovic, T. (2020). Increased activation of the fear neurocircuitry in children exposed to violence. Depression and anxiety, 37(4), 303-312.

[36] Wilson, W. C., \& Rosenthal, B. S. (2003). The relationship between exposure to community violence and psychological distress among adolescents: A meta-analysis. Violence and Victims, 18, 335-352 